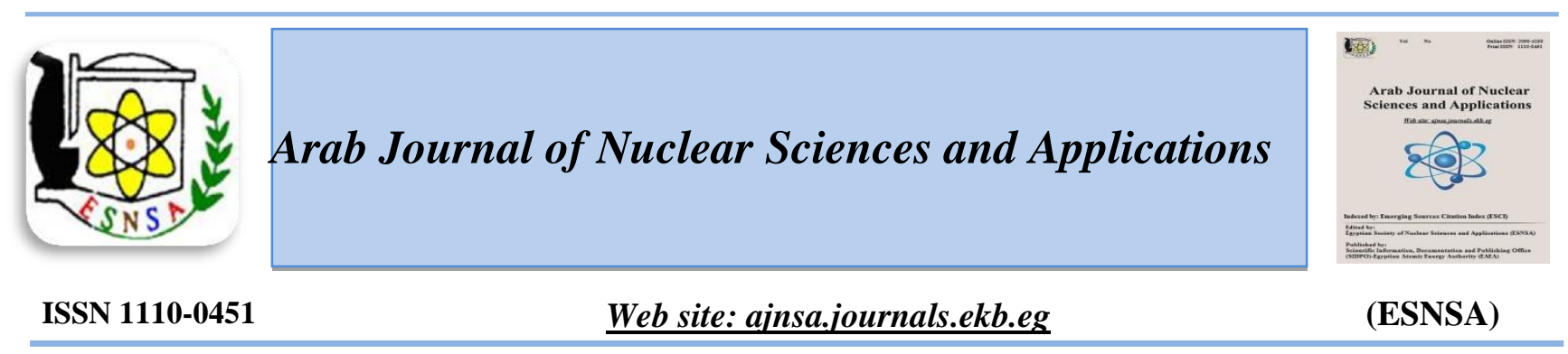

\title{
A Study on Protection Against the Radioactive Hazards During Transportation of Naturally Occurring Radioactive Materials
}

\author{
A. M. Massoud \\ Department of Physics, Faculty of Science, Ain Shams University, Cairo, Egypt
}

\begin{abstract}
Received $23^{\text {rd }}$ Dec. 2018 In this work, radiation dosages and hazards emerging due to doses received by drivers and workers Accepted $10^{\text {th }}$ Feb. 2019 involved in transporting naturally occurring radioactive materials (NORM) in Egypt are assessed and compared with the accepted doses in many countries. Two cases were studied; the first case is of a truck driver and the other one was of the loading-unloading workers. The workers' case was studied to estimate the doses and hazards to workers in the field of recycling materials. The annual working hours for truck drivers were defined, according to normal, heavy and abnormal duties, as 200, 400 and 600 hours. Working hours for loading-unloading workers were also selected under various conditions of duties to be 50,100 and 150 annual hours. External and internal exposure for drivers and workers were estimated according to the properties of materials. Zircon, phosphate and bauxite were the assumed cargos. The doses due to inhalation of contaminated dust were considered in addition to the external dose of $\mathrm{g}$ - radiation.
\end{abstract}

\section{Introduction}

Keywords: Radiation, Hazards, NORM, Exposure dose
Transport workers may face hazards due to certain radioactive materials that are contained in some goods. These include dealing with radioactive sources or handling materials containing high concentrations of naturally occurring radioactive materials (NORM) [1]. The International Atomic Energy Agency (IAEA) set the protocols of safety for the radioactive stuff's transportation [2, 3]. According to these protocols, the radioactive materials are defined as those materials which have radionuclides of both activity concentration and total activity, in the shipment, exceeding the exemption levels for those radionuclides. Permitive materials that have low values of radioactivity are imported and processed in many industries. Ilmenite and rutile contain radioactive Uranium-238 and Thorium-232 [4] is used to extract pigment titanium dioxide. These materials are shipped by marine tankers and railways in bulks. Also, production of refactory bricks, ceramic, glasses and the high temperature casting are utilizing zircon which is normally bagged during transport [5].These materials are outside the transport regulation scope because the radioactivity concentrations are not much higher than the exemption concentrations of uranium and thorium. Therefore, a common assessment was carried out to evaluate the levels of potential radiation exposure of workers involved in the transport operations. The transport of zircon flour was used as an example to calculate the dose rate. IAEA has introduced an international research program to examine the transport of NORM and this study is a contribution to that research [6]. Many NORM materials were studied [7]. Transport of zircon, phosphate and bauxite is examined in the current study. Valuation has been made of the radiological influence during the transport operations.

Corresponding author: amassouda1@yahoo.com

DOI: 10.21608/ajnsa.2019.6816.1160

(C) Scientific Information, Documentation and Publishing Office (SIDPO)-EAEA 


\section{Sample preparation}

A database is built to collect information during the NORM investigation. It was possible to identify several firms that are importing stuffs containing NORM. Different types of raw material (zircon, phosphate and bauxite) with high activity concentrations were collected from factories. The samples were transferred to the Egyptian Nuclear and Radiological Regulatory Authority, Central Laboratory for Environmental Radioactivity Measurements Inter-comparison and Training (CLERMIT) for preparation and analysis. $\mathrm{Ra}\left({ }^{238} \mathrm{U}\right.$ series), Th-series, and K-40 activities were measured using $\gamma$-spectrometry based on hyperpure germanium detectors (HPGe). HPGe detector are of $40 \%$ relative efficiency and $1.95 \mathrm{keV}$ FWHM for ${ }^{60} \mathrm{Co} \gamma$ - energy line at $1332 \mathrm{keV} . \gamma-$ acquisition and analysis were carried out using Canberra Genie 2000. Activity calculations were made using the following $\gamma$ - transmissions: 351.9 $\left({ }^{214} \mathrm{~Pb}\right), 609.3,1120.3$ and $1764.5 \mathrm{keV}\left({ }^{214} \mathrm{Bi}\right)$ for the ${ }^{226} \mathrm{Ra}$-series, 338.4, 911.1 and $968.9 \mathrm{keV}$ $\left({ }^{228} \mathrm{Ac}\right)$ for Th- series, and $1460.7 \mathrm{keV}$ for ${ }^{40} \mathrm{~K}$. A point source of ${ }^{226} \mathrm{Ra}$ and a $\mathrm{KCl}$-standard solutions were used to calibrate the $\gamma$-spectrometers [8].

\section{Estimation of effective dose}

$\gamma$-radiation external, inhalation, and exposure effective dose due to transporting of zircon, phosphate, and bauxite materials were calculated using the following equations [9]:

$\mathrm{E}_{\text {ext }}=A D_{\text {ext }} T_{\mathrm{e}} \mathrm{F}_{\mathrm{d}}$

$E_{\text {inh }}=A D_{\text {inh }} T_{e} F_{d} B_{r} C_{\text {dust }}$

$E_{\text {ing }}=A D_{\text {ing }} T_{e} F_{d} R_{\text {ing }}$

Where;

$E_{\text {ext }}$ is the external $\gamma$-radiation effective dose ( $\mathrm{Sv}$ $\mathrm{y}^{-1}$ );

$\mathrm{E}_{\text {inh }}$ is the inhalation effective dose $\left(\mathrm{Sv} \mathrm{y}^{-1}\right)$;

$\mathrm{E}_{\text {ing }}$ is the ingestion effective dose $\left(\mathrm{Sv} \mathrm{y}^{-1}\right)$;

$\mathrm{A}$ is the samples activity concentration in $\left(\mathrm{Bq} \mathrm{g}^{-1}\right)$;

$D_{\text {ext }}$ is the dose coefficient for external $\gamma$-radiation $\left(\mathrm{Sv} \mathrm{h}^{-1} \mathrm{~Bq} \mathrm{~g}^{-1}\right)$;

$D_{\text {inh }}$ is the dose coefficient for inhalation exposure $\left(\mathrm{Sv} \mathrm{g}^{-1}\right)$;

$\mathrm{D}_{\text {ing }}$ is the dose for ingestion exposures $\left(\mathrm{Sv} \mathrm{g}^{-1}\right)$;

$\mathrm{T}_{\mathrm{e}}$ is the time of exposure $\left(\mathrm{y}^{-1}\right)$;

$F_{d}$ is the dilution factor;

$B_{r}$ is the rate of breathing $\left(\mathrm{m}^{3} \mathrm{~h}^{-\mathbf{1}}\right)$;

$\mathrm{C}_{\text {dust }}$ is the concentration of dust during exposure $\left(\mathrm{g} \mathrm{m}^{-3}\right)$;

$\mathrm{R}_{\mathrm{in}}$ is the rate of ingestion rate $\left(\mathrm{g} \mathrm{h}^{-1}\right)$.
Determination of transportation circumstances These doses were evaluated according to the work rehearses set up. Driving periods, vehicles loading and distance from the material were taken into consideration to describe the transport operations and develop exposure circumstances. Doses were generally calculated for vehicle drivers transporting materials in a conveyance and for individuals involved in loading materials. For each of these materials, experts categorized the radionuclides, activity concentrations and the transported volumes, as well as other aspects of the process such as the typical loading and the types of shipment containing NORM.

\section{a-External exposure for a vehicle driver}

The following assumptions have been developed to deal with this case:

The shipment is assumed to be a parallelepiped of a $20 \mathrm{~m}^{3}$ volume, of dimensions $2 \times 2 \times 5 \mathrm{~m}$. The density of the material is assumed to be $1500 \mathrm{~kg}$ $\mathrm{m}^{-3}$, therefore the mass is assumed to be 30 tons. The truck walls are assumed to be made of steel of $1 \mathrm{~cm}$ thickness of. The shipment is positioned to be $1 \mathrm{~m}$ from the driver.

As for the loading-unloading process, the following circumstances are considered:

(1) Loading, transport and unloading process takes about 4 hours.

(2) Annual exposure period of 200, 400, or $600 \mathrm{~h}$, depending on the numbers of trips that are done by the driver. Where the $200 \mathrm{~h}$ is considered to be a normal duty, $400 \mathrm{~h}$ is for the heavy duty and the $600 \mathrm{~h}$ is taken in the case of abnormal working conditions.

$b$-External exposure for loading-unloading worker:

In case of the worker, it is assumed that the worker is exposed for 1,2 , and 3 hours per week with annual duty of 50 weeks which results in an annual exposure period of 50, 100, and 150 hours respectively. Also, exposure pathway inhalation must be considered because the worker is exposed to dust during handling bulk bags.

\section{c-Internal exposure}

To predict the rates of internal dose for dust inhalation and ingestion, the following assumptions are considered:

1- The concentration of the dust is $1 \mathrm{mg} \mathrm{m}^{-3}$;

2- The dust rate of ingestion is $1 \mathrm{mg} \mathrm{h}^{-1}$; 
3- The worker's breathing rate is $1.2 \mathrm{~m}^{3} \mathrm{~h}^{-1}$ [10];

4- The inhaled particle size is $5 \mu \mathrm{m}$;

5- Radionuclides that are contained in the dust have activity concentration of $1 \mathrm{~Bq} \mathrm{~g}^{-1}$;

6-Exposure distance is $1 \mathrm{~m}$ without assuming shielding.

7-The lung clearance for uranium and thorium is of S-type [11];

8-The lung clearance type for other elements is as mentioned in a previous study [11].

\section{Results and Discussion}

Activity concentrations of the transported materials

Depending on the type of transported NORM, the effective dose per year is evaluated for both the driver and the worker. A wide range of ${ }^{226} \mathrm{Ra}\left({ }^{238} \mathrm{U}\right.$ series) and ${ }^{232} \mathrm{Th}$ activity concentrations in zirconium, bauxite and phosphate minerals were measured and reported as shown in Table (1).

\section{Annual exposure effective dose}

Table (2) shows the calculated annual effective doses, which are received to the driver and worker, depending on the concentration activity of each radionuclide. Annual effective doses in normal work range from 20.4 to 62.6 , and from 5.3 to 16.2 $\mu \mathrm{Sv}$ for vehicle driver and loading-unloading worker, respectively. In the case of hard work, annual effective doses are range from 40.7 to 125.2 , and from 10.5 to $32.4 \mu \mathrm{Sv}$ for vehicle driver and loading-unloading worker respectively. Also, in abnormal work, the annual effective doses range from 61.1 to 187.8 , and from 15.7 to $48.6 \mu \mathrm{Sv}$ for vehicle driver and loading-unloading worker, respectively. Figure $1(\mathrm{a}, \mathrm{b})$ presents the annual effective dose for vehicle driver at 200, 400, and $600 \mathrm{~h}$ and loading-unloading workers at 50, 100, and $150 \mathrm{~h}$ during transportation scenario of Zircon, Bauxite, and Phosphate. According to the IAEA safety guide TS-R-1 [12], and European Commission, practical use of the concepts of clearance and exemption (2002) (Part II) [13], the recommended annual effective doses for safe transport of NORM range from 0.005 to $10 \mathrm{mSvh}^{-1}$.

In NUREG-1717 [14], doses were estimated using a microshield and assuming that a 48 pallet (50 bags $41 \mathrm{~kg}$ per pallet) of $0.05 \%$ by weight uranium and thorium in zircon flour were transported with an exposure duration of $24 \mathrm{~h}$ to transport 1 load and 25 trips per year (600 hours per year) by the same driver. Based on these assumptions, the estimated annual dose to the truck driver was estimated to be $0.06 \mathrm{mSv}$. Doses were also estimated using a micro-shield by the Health Protection Agency, Radiation Protection

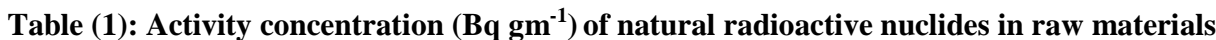

\begin{tabular}{|c|c|c|c|}
\hline Sample type & Ra-226 & Th-232 & K-40 \\
\hline Zircon Bally & $3914.1 \pm 15.5$ & $1205.7 \pm 101.3$ & $110.2 \pm 12.3$ \\
\hline Zircon flour & $2400.4 \pm 5$ & $427.4 \pm 8.5$ & $7.6 \pm 10.2$ \\
\hline Zircon batch & $2740.1 \pm 21.6$ & $521.4 \pm 24.8$ & $107.3 \pm 4.6$ \\
\hline Zirconia Ramming material & $3354.4 \pm 9.2$ & $829.7 \pm 0.3$ & $68.4 \pm 10.8$ \\
\hline Zirconia Powder & $3597.5 \pm 8.5$ & $872.1 \pm 0.3$ & $129.3 \pm 9.8$ \\
\hline Bauxite & $2153.7 \pm 11$ & $372.7 \pm 9.7$ & $1336.4 \pm 22.1$ \\
\hline Phosphate Raw material & $1180.6 \pm 0.3$ & $16 \pm 20.1$ & $1582 \pm 0.6$ \\
\hline
\end{tabular}

Table (2): Annual Effective Dose in $\mu \mathrm{Sv}^{-1}$ for Transport Scenarios

\begin{tabular}{|c|c|c|c|c|c|c|}
\hline \multirow{2}{*}{ NORM } & \multicolumn{3}{|c|}{ Driver } & \multicolumn{4}{c|}{ Loading- Unloading Workers } \\
\cline { 2 - 7 } & $\mathbf{2 0 0} \mathbf{~ h}$ & $\mathbf{4 0 0} \mathbf{~ h}$ & $\mathbf{6 0 0} \mathbf{~ h}$ & $\mathbf{5 0 ~ h}$ & $\mathbf{1 0 0} \mathbf{~ h}$ & $\mathbf{1 5 0} \mathbf{~ h}$ \\
\hline Zircon(MAX) & $62.6 \pm 0.5$ & $125.2 \pm 0.9$ & $187.8 \pm 1.5$ & $16.2 \pm 0.1$ & $32.4 \pm 0.37$ & $48.6 \pm 0.4$ \\
\hline Zircon(MIN) & $37.6 \pm 0.1$ & $75.1 \pm 0.2$ & $112.7 \pm 0.3$ & $9.72 \pm 0.03$ & $19.4 \pm 0.1$ & $29.2 \pm 0.1$ \\
\hline Bauxite & $35.7 \pm 0.2$ & $71.4 \pm 0.4$ & $107.1 \pm 0.7$ & $9.22 \pm 0.1$ & $18.4 \pm 0.1$ & $27.7 \pm 0.2$ \\
\hline Phosphate & $20 . \pm 0.01$ & $40.7 \pm 0.01$ & $61.1 \pm 0.02$ & $5.25 \pm 0.0014$ & $10.5 \pm 0.01$ & $15.8 \pm 0.01$ \\
\hline
\end{tabular}


Division [4]. It was assumed that 20 tons of zircon flour was transported with the following radionuclide concentrations: $3 \mathrm{~Bq} \mathrm{~g}^{-1}$ of ${ }^{238} \mathrm{U}, 0.15$ $\mathrm{Bq} \mathrm{g}^{-1}$ of ${ }^{235} \mathrm{U}$ and $0.6 \mathrm{~Bq} \mathrm{~g}^{-1}$ of ${ }^{232} \mathrm{Th}$. The driver was assumed to be $1 \mathrm{~m}$ away from the load surface and to have an annual driving time of $600 \mathrm{~h}$, resulting in an annual dose of about $0.18 \mathrm{mSv}(3 \mathrm{x}$ $10^{-4} \mathrm{mSv} \mathrm{h}^{-1}$ ). In the present study, the maximum total effective dose for zircon ore was $188 \pm 1.5$ $\mu \mathrm{Sv}$, which was the highest among other ores.

Table (3) shows a comparison of the annual effective dose between maximum result of the present study and different countries in $\mathrm{mSv}$ for zircon material transport scenarios. These results agree with the average values of worldwide for annual period of $600 \mathrm{~h}$. Estimated doses based on
$10 \mathrm{~Bq} \mathrm{~g}^{-1}$ exemption concentration [15], in transportation approach to evaluating the dose and actual activity concentration data is to determine the doses that would result if the activity concentration was $10 \mathrm{~Bq} \mathrm{~g}^{-1}$. Multiplying by a ratio of the normalized doses (annual exposure duration of $400 \mathrm{~h}$ ) over the actual activity concentrations, the estimated doses associated with $10 \mathrm{~Bq} \mathrm{~g}^{-1}$ for the ores and products, ranged from 0.01 to 0.4 $\mathrm{mSv}$. An average annual dose was estimated to be about $0.1 \mathrm{mSv}$. According to the International commission on radiological protection ICRP [17], the current assessed doses are considerably lower than the practical dose constraint of $1 \mathrm{mSv}$ and within the range of the prudent dose constraint of $0.1 \mathrm{mSv}$.

Table (3): A comparison between the current results and the annual effective dose in some countries at the same exposure

\begin{tabular}{|l|l|l|l|l|}
\hline Country & $\begin{array}{l}\text { Annual effective } \\
\text { dose }\left(\boldsymbol{\mu S v} \mathbf{y}^{-1}\right)\end{array}$ & Material & $\begin{array}{l}\text { Annual } \\
\text { exposure } \\
\text { period (h) }\end{array}$ & Reference \\
\hline NUREG 1717 & 60 & Zircon flour & 600 & {$[14]$} \\
\hline UK & 180 & Zircon flour & 600 & {$[4]$} \\
\hline USA & 59 & Zircon & 600 & {$[15]$} \\
\hline Australia & 180 & Zircon flour & 600 & {$[16]$} \\
\hline Current study & 188 & Zircon & 600 & \\
\hline
\end{tabular}
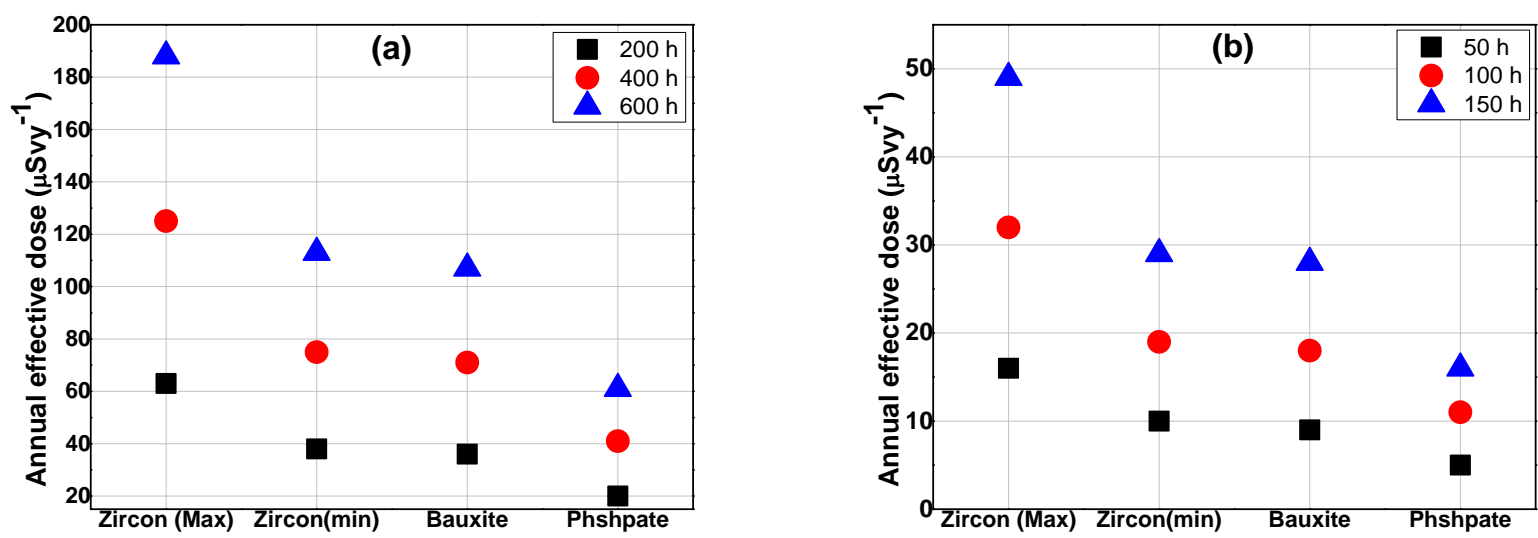

Fig. (1): Annual effective dose for the (a) truck driver and (b) loading-unloading worker according to the transport scenario 


\section{Conclusion}

The aim of the current study is developing scenarios according to the working hours and materials type to determine the annual effective dose of external $\gamma$-radiation, inhalation, and exposure received by the driver in the case of working for 600 hours per year as maximum working hours. According to IAEA safety guide TS-R-1, the annual recommended dose ranges from 0.005 to $10 \mathrm{mSv} \mathrm{h}^{-1}$. The calculated annual dose is $188 \mu \mathrm{Sv}\left(3.13 \times 10^{-4} \mathrm{mSv} \mathrm{h}^{-1}\right)$. This value is suggested if 20 tons of zircon flour with $3 \mathrm{~Bq} \mathrm{~g}^{1}$ of ${ }^{238} \mathrm{U}$ and, $0.15 \mathrm{~Bq} \mathrm{~g}^{-1}$ of ${ }^{235} \mathrm{U}$ and $0.6 \mathrm{~Bq} \mathrm{~g}^{-1}$ of ${ }^{232} \mathrm{Th}$ is transported. This estimated value is the highest among all other ores. Therefore, the exposure of workers of all materials does not need to be controlled.

\section{Acknowledgement}

The author would like to acknowledge the Central Laboratory for Environmental Radioactivity Measurements Inter-comparison and Training (CLERMIT), The Egyptian Nuclear and Radiological Regulatory Authority, for the sincere help and support during the execution of this study.

\section{References}

1-Chowdhury, S.; Husain, T.; Veitch, B.; Bose, N.; Sadiq, R. (2004): Human health risk assessment of naturally occurring radioactive materials in produced water - a case study, Human and Ecological Risk Assessment, 10, 6, pp. 1155-1171.

2-IAEA safety standards series, for protecting people and the environment, Regulations for the Safe Transport of Radioactive Material Specific Safety Requirements No. SSR-6 (Rev. 1) 2018 Edition,

3-IAEA safety standards series, "Assessment of Occupational Exposure Due to Intakes of Radionuclides", SAFETY GUIDE No. RS-G-1.2.

4-M. I. Idris, K.K. Siong and S.M. Fadzil (2018): Measurement of $238 \mathrm{U}$ and $232 \mathrm{Th}$ radionuclides in ilmenite and synthetic rutile, Materials Science and Engineering 298, 012010.

doi:10.1088/1757-899X/298/1/012010

5-J. S. Hughes and M. P. Harvey (2008): A study on the transport of naturally occurring radioactive materials, , ISBN 978-0-85951-615-0.

6-Measures to strengthen international cooperation in nuclear, radiation, transport and waste safety, IAEA General Conference Resolutions GC(53)/RES/10, para $65 ; \mathrm{GC}(54) / \mathrm{RES} / 7$, para 54; GC(55)/RES/9, para 66; GC(56)/RES/9, para 64; GC(57)/ RES/9, para 86; GC(58)/RES/10, para 90, IAEA, Vienna (2009-2014)
7-K.K. Varley (2010): The appropriate level of regulatory control for the safe transport of NORM, , Proceedings of an International Symposium Marrakesh, Morocco, 22-26 March 2010.

8-M. S. El-Tahawy, M. A. Farouk, F. H. Hammad and N. M. Ibrahim (1992): Natural Potassium as a Standard Source for the Absolute Efficiency Calibration of Germanium Detectors, Journal of Nuclear Science, Vol. 29, No. 1, pp. 361-363.

9-Iwaoka K., Keiko Tagami, Hidenori Yonehara (2009): Measurement of natural radioactive nuclide concentrations in various metal ores used as industrial raw materials in Japan and estimation of dose received by workers handling them, Journal of Environmental Radioactivity 100, 993-997.

10-ICRP Publication 60, 1991

11-Commission on radiological protection, dose coefficients for Intakes of Radionuclides by Workers, Publication 68, Pergamon, Oxford (1994).

12-International Atomic Energy Agency, Regulations for the Safe Transport of Radioactive Material, 2009 Edition, IAEA Safety Standards Series No. TS-R-1, IAEA, Vienna (2005).

13-EC, 2002. European Commission, Practical Use of the Concepts of Clearance and Exemption (Part II). EC, Belgium.

14-NUREG 1717 (2001),"Systematic radiological assessment of exemptions for source and byproduct materials".

15-ORNL 2010, Oak Ridge National Laboratory, "Evaluation of activity concentration values and Doses due to the Transport of low-level radioactive material", Environmental Protection and Waste Services Division, USA.

16-Callithrix. 2008, Radiation Exposure in the Transport of Heavy Mineral Sands; Report for the Australian Radiation Protection and Nuclear Safety Agency (ARPANSA). Calytrix Consulting Pty Ltd, September http://www.arpansa.gov.au/pubs/rps/rps2calytrix.pdf

17-ICRP Pub. 103, 2007, International Commission on Radiological Protection (ICRP). 2007. ICRP Publication 103, The 2007 Recommendations of the International Commission on Radiological Protection, Annals of the ICRP, 37, 2-4. 